\title{
Should we admit more patients not requiring invasive ventilation to reduce excess mortality in Polish intensive care units? Data from the Silesian ICU Registry
}

Piotr Knapik ${ }^{1}$, Małgorzata Knapik ${ }^{1}$, Ewa Trejnowska ${ }^{1}$, Bogumiła Kłaczek ${ }^{1}$, Konstanty Śmietanka ${ }^{1}$, Daniel Cieśla², Łukasz J. Krzych³, Ewa M. Kucewicz

${ }^{1}$ Department of Anaesthesiology, Intensive Therapy and Emergency Medicine, Silesian Centre for Heart Diseases, Medical University of Silesia, Zabrze, Poland 2Department of Science, Education and New Medical Technologies, Silesian Centre for Heart Diseases, Zabrze, Poland

${ }^{3}$ Department of Anaesthesiology and Intensive Care, School of Medicine,

Medical University of Silesia, Katowice, Poland

Submitted: 24 October 2018

Accepted: 3 February 2019

Arch Med Sci 2019; 15 (5): 1313-1320

DOI: https://doi.org/10.5114/aoms.2019.84401

Copyright (c) 2019 Termedia \& Banach

\section{Abstract}

Introduction: Mortality in Polish intensive care units (ICU) is excessively high. Only a few patients do not require intubation and invasive ventilation throughout the whole ICU treatment period. We aimed to define this population, as pre-emptive admissions of such patients may increase the population which benefits from ICU admission and reduce excessive mortality in Polish ICUs.

Material and methods: Data on 20651 patients from the Silesian Registry of Intensive Care Units were analysed. Patients who did not require intubation and invasive ventilation (referred to as non-ventilated patients) were identified and compared to the remaining ICU population. Independent variables that influence being non-intubated in the ICU were identified.

Results: Among 20368 analyzed adult patients, only 1233 (6.1\%) were in the non-ventilated group. Non-ventilated patients were younger, with fewer comorbidities and a lower APACHE II score at admission (13.0 \pm 7.1 vs. $23.7 \pm 8.6$ points, $p<0.001$ ). Patients with cardiac arrest prior to admission were particularly rare in this group ( $2.6 \%$ vs. $26.8 \%, p<0.001)$. The ICU mortality among non-ventilated patients was 6 to 7 times lower $(7.0 \%$ vs. $46.7 \%, p<0.001)$. Independent variables that influenced the ICU stay in non-ventilated patients were: obstetric complications as the primary cause of ICU admission, presence of a systemic autoimmune disease, invasive monitoring as the primary cause of ICU admission, ICU readmission and the presence of cancer.

Conclusions: Non-ventilated patients have a high potential for a favourable outcome. Pre-emptive ICU admissions have a potential to reduce mortality in Polish ICUs.

Key words: mechanical ventilation, intensive care units, risk assessment, mortality.

\section{Introduction}

It has been recently confirmed that mortality in the intensive care units (ICUs) in Poland is higher than in other European countries [1, 2]. This problem is not associated with an inferior quality of care, as the

\author{
Corresponding author: \\ Prof. Piotr Knapik \\ Department \\ of Anaesthesiology, \\ Intensive Therapy \\ and Emergency Medicine \\ Silesian Centre \\ for Heart Diseases \\ Medical University of Silesia \\ 9 M. Curie-Skłodowskiej St \\ 41-800 Zabrze, Poland \\ E-mail:pknapik@sum.edu.pl
}


observed mortality is lower than predicted according to well-established ICU scoring systems [3]. In many Polish hospitals, a dying patient, or one without a chance for survival, is still immediately (or eventually) transferred to the ICU. A modification to the way this part of the health care system operates is necessary as soon as possible.

There is a common belief amongst intensivists that a vast majority of patients admitted to ICUs in Poland require intubation and mechanical ventilation. There are however no data to support this and daily observations show that there are still few patients who do not require intubation and mechanical ventilation, both at the time of ICU admission and throughout the ICU stay. It is unclear how large this population is, what sort of patients is it composed of and why is it possible to avoid invasive ventilation during ICU stay in these patients. Moreover, we do not know whether avoiding invasive ventilation has a significant impact on the outcome in this group of patients.

It seems that the fraction of non-ventilated ICU patients in other countries is relatively high [4-6], but there is a lack of precise information on this subject in the medical literature. It may be assumed that a non-ventilated population admitted to the ICU at an early stage will benefit most from such escalation of care, requiring much less resources at a later time [7]. Therefore, pre-emptive ICU admissions contribute to the reduction in mortality and are cost-effective [8, 9]. In many Western countries, non-ventilated deteriorating patients are routinely identified at an early stage by ICU outreach teams, as a result of early warning scoring systems that are effectively operating

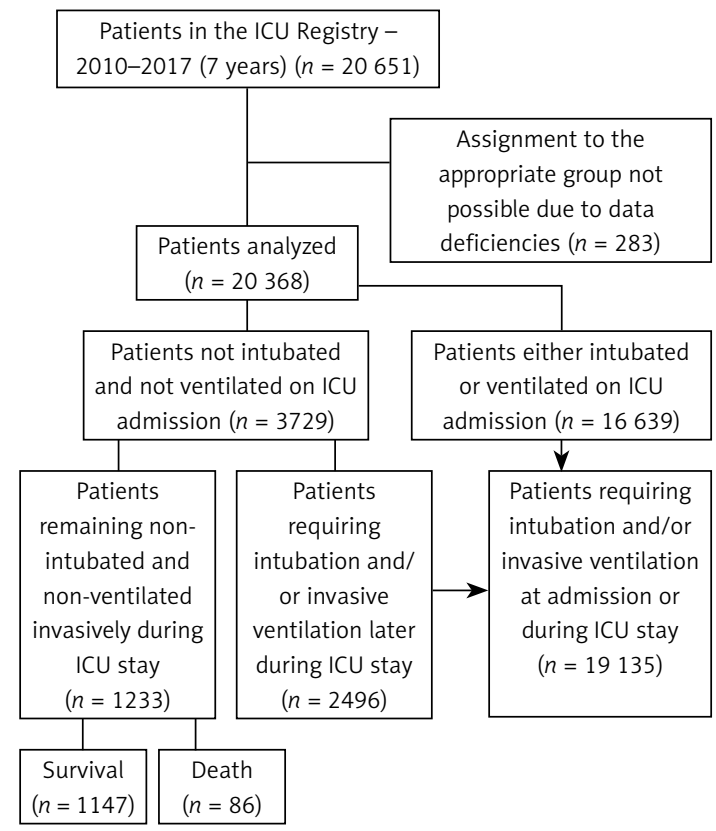

Figure 1. Distribution of patients in the analysed population within hospitals [10-12], although the benefits of using such systems have not been fully confirmed [13]. So far, these issues have not been the concern of any scientific publication that focused on the Polish health care system. Such changes also have the potential to influence the ICU staff to better perceive the outcomes of care they are providing [14]. Exploration of these issues may pave the way to the restructuring of admissions to Polish ICUs and the consequent reduction of excessive ICU mortality.

The aim of this study was to define the non-ventilated population and identify independent variables that influence being non-intubated and not invasively ventilated in Polish ICUs.

\section{Material and methods}

This analysis was based on a multicentre study and included a population of patients hospitalized in ICUs reporting to the Silesian Registry of Intensive Care Units in the Silesian Region of Poland (representing approximately $35 \%$ of all Silesian ICUs). The Silesian ICU Registry has operated in the Silesian Region of Poland since October, 2010. Data on 20651 hospitalizations from October, 2010 to September, 2017 (7 years) were analysed. 283 hospitalizations (1.4\%) were excluded from the analysis (as assignment to the appropriate group was not possible due to deficiencies in data). Finally, overall 20368 hospitalizations were analysed (Figure 1).

The Silesian ICU Registry collects information on the health burden of patients admitted to reporting ICUs, patients' general condition on admission, causes of admissions, the treatment process and outcomes. Exhaustive description of the structure and methodology of the Silesian ICU Registry has already been described elsewhere [15]. Due to the retrospective and anonymous nature of our study, the Ethical Committee at the Medical University of Silesia in Katowice waived the need for consent of patients to participate in the study. Due to the lack of personal data in the registry, we were not able to identify individual patients; therefore in the whole text we used the word "patients", but in fact this term stands for individual hospitalizations.

Data of 20368 patients in the registry were analysed. All patients who did not require intubation and/or invasive ventilation both on ICU admission and throughout the ICU stay were identified and compared to the remaining population. Variables defining the patients' condition prior to or at ICU admission and influencing further treatment were analysed. Demographic parameters, co-morbidities, severity of the condition at ICU admission, main reasons for ICU admission, treatment used and clinical outcomes were all compared. 


\section{Statistical analysis}

Statistica 13.0 PL software was used for statistical analysis. Demographic data were presented using descriptive statistics and compared using Student's t-test or the Mann-Whitney test (the choice of the test was dependent on the result of the Kolmogorov-Smirnov test). For comparison of qualitative variables, the $\chi^{2}$ test with Yates' correction was used. Independent preadmission variables influencing the lack of invasive ventilation at ICU admission and during the ICU stay were identified. The effect of independent variables on the outcome variable of interest was calculated by means of univariate logistic regression. Variables with a $p<0.05$ were then included in the multivariate logistic regression analysis. The multivariable model was fitted using the stepwise method, where $p<0.05$ was set as the inclusion and removal criterion. For the purposes of all calculations, statistical significance was accepted at the significance level of $p<0.05$.

\section{Results}

Among 20368 analysed patients, 3729 (18.3\%) did not require intubation and invasive ventilation on ICU admission. In this group, 2496 patients $(66.9 \%)$ required intubation or tracheostomy (and

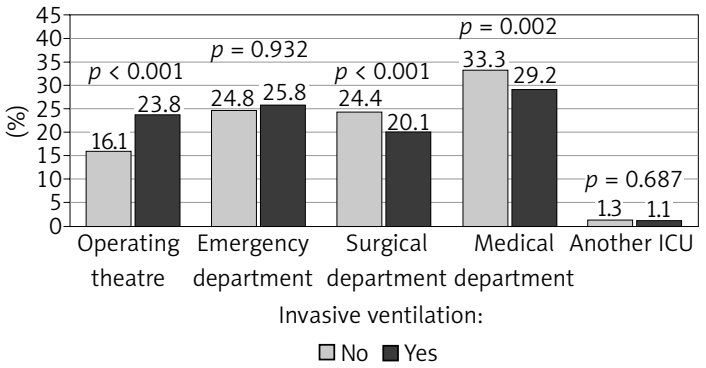

Figure 2. Source of ICU admission

subsequently invasive ventilation) later during their treatment. Only 1233 (33.1\%) patients did not require any of these methods for the entire period of ICU stay. Thus, patients who did not require intubation and invasive ventilation on admission, and did not require any of these methods for the entire period of ICU stay (referred to hereinafter as "non-ventilated patients") constituted only $6.1 \%$ of the overall ICU population (Figure 1).

Non-ventilated patients were most often admitted to ICUs from medical departments (Figure 2). There were also more ICU readmissions in this population (Table I).

The comparison of basic demographic variables of non-ventilated patients with the rest of the population showed that the percentage of wom-

Table I. Medical status on ICU admission

\begin{tabular}{|c|c|c|c|c|}
\hline Medical status & & $\begin{array}{l}\text { Non-ventilated } \\
\quad(n=1233)\end{array}$ & $\begin{array}{l}\text { Ventilated } \\
(n=19135)\end{array}$ & $P$-value \\
\hline \multirow[t]{3}{*}{ Admission } & First & $1127(91.4 \%)$ & $18105(94.6 \%)$ & $<0.001$ \\
\hline & Second & $90(7.3 \%)$ & $924(4.8 \%)$ & $<0.001$ \\
\hline & Another & $16(1.3 \%)$ & $106(0.6 \%)$ & 0.002 \\
\hline \multirow[t]{19}{*}{ Co-morbidities } & Coronary artery disease & $376(30.5 \%)$ & 8309 (43.4\%) & $<0.001$ \\
\hline & Heart failure & $391(31.7 \%)$ & $6828(35.7 \%)$ & 0.005 \\
\hline & Arterial hypertension & $535(43.4 \%)$ & $9719(50.8 \%)$ & $<0.001$ \\
\hline & Disseminated atherosclerosis & $277(22.5 \%)$ & $6825(35.7 \%)$ & $<0.001$ \\
\hline & Chronic respiratory failure & $129(10.5 \%)$ & $2319(12.1 \%)$ & 0.091 \\
\hline & Home oxygen therapy & $23(1.9 \%)$ & $302(1.6 \%)$ & 0.508 \\
\hline & Extreme obesity & $68(5.5 \%)$ & $1037(5.4 \%)$ & 0.937 \\
\hline & Cachexia & $60(4.9 \%)$ & $692(3.6 \%)$ & 0.029 \\
\hline & Alcoholism & $72(5.8 \%)$ & $1793(9.4 \%)$ & $<0.001$ \\
\hline & Diabetes & $274(22.2 \%)$ & $4734(24.7 \%)$ & 0.050 \\
\hline & Chronic renal failure & $160(13.0 \%)$ & $2790(14.6 \%)$ & 0.131 \\
\hline & Dialysis dependency & $19(1.5 \%)$ & $239(1.2 \%)$ & 0.449 \\
\hline & Previous cerebral stroke & $70(5.7 \%)$ & $1381(7.2 \%)$ & 0.048 \\
\hline & Chronic neurological disorders & $97(7.9 \%)$ & $1502(7.8 \%)$ & 0.974 \\
\hline & Systemic autoimmune diseases & $36(2.9 \%)$ & $188(1.0 \%)$ & $<0.001$ \\
\hline & Post-transplant & $1(0.1 \%)$ & $40(0.2 \%)$ & 0.520 \\
\hline & Cancer & $120(9.7 \%)$ & $1349(7.0 \%)$ & $<0.001$ \\
\hline & Pregnancy & $8(0.6 \%)$ & $32(0.2 \%)$ & $<0.001$ \\
\hline & None & $160(13.0 \%)$ & 1766 (9.2\%) & $<0.001$ \\
\hline
\end{tabular}


Table II. Primary reason for ICU admission

\begin{tabular}{|lccc|}
\hline Primary reason & $\begin{array}{c}\text { Non-ventilated } \\
(n=1233)\end{array}$ & $\begin{array}{c}\text { Ventilated } \\
(n=19135)\end{array}$ & $P$-value \\
\hline Shock & $172(13.9 \%)$ & $6043(31.6 \%)$ & $<0.001$ \\
\hline Cardiac arrest & $32(2.6 \%)$ & $5128(26.8 \%)$ & $<0.001$ \\
\hline Postoperative & $287(23.3 \%)$ & $5630(29.4 \%)$ & $<0.001$ \\
\hline Multiple trauma & $74(6.0 \%)$ & $668(3.5 \%)$ & $<0.001$ \\
\hline Craniocerebral trauma & $35(2.8 \%)$ & $930(4.9 \%)$ & 0.002 \\
\hline Acute pancreatitis & $20(1.6 \%)$ & $299(1.6 \%)$ & 0.964 \\
\hline Obstetric complications & $14(1.1 \%)$ & $49(0.3 \%)$ & $<0.001$ \\
\hline Acute neurological disorders & $74(6.0 \%)$ & $1374(7.2 \%)$ & 0.133 \\
\hline Intoxication & $24(1.9 \%)$ & $304(1.6 \%)$ & 0.395 \\
\hline Severe metabolic disorders & $59(4.8 \%)$ & $1067(5.6 \%)$ & 0.265 \\
\hline Sepsis & $112(9.1 \%)$ & $1272(6.6 \%)$ & 0.001 \\
\hline Advanced monitoring & $834(67.6 \%)$ & $10636(55.6 \%)$ & $<0.001$ \\
\hline
\end{tabular}

Table III. The ICU treatment

\begin{tabular}{|lccc|}
\hline Treatment & $\begin{array}{c}\text { Non-ventilated } \\
(n=1233)\end{array}$ & $\begin{array}{c}\text { Ventilated } \\
(n=19135)\end{array}$ & $P$-value \\
\hline Catecholamines & $465(37.7 \%)$ & $14246(74.4 \%)$ & $<0.001$ \\
\hline Tracheostomy & $0(0.0 \%)$ & $3366(17.6 \%)$ & - \\
\hline Renal replacement therapy & $88(7.1 \%)$ & $1814(9.5 \%)$ & 0.007 \\
\hline Operation while in the ICU & $43(3.5 \%)$ & $1795(9.4 \%)$ & $<0.001$ \\
\hline Intra-aortic balloon pump & $23(1.9 \%)$ & $524(2.7 \%)$ & 0.081 \\
\hline ECMO & $0(0.0 \%)$ & $63(0.3 \%)$ & 0.080 \\
\hline
\end{tabular}

en in both groups was similar (44.1\% vs. $41.6 \%$, $p=0.089$ ), but non-ventilated patients were younger ( $58.8 \pm 19.0$ vs. $64.4 \pm 15.5$ years, $p<0.001)$ and less likely to have additional co-morbidities. They were also more likely to be pregnant, have systemic autoimmune disease and cancer. Medical status of both groups on ICU admission is shown in Table I.

Distribution of primary reasons for ICU admission varied between groups. Cardiac arrest prior to ICU admission was uncommon among non-ventilated patients, while it was present in over a quarter of the remaining population $(2.6 \%$ vs. $26.8 \%, p<0.001)$. An opposite situation was found among other variables. A higher percentage of non-ventilated patients were admitted to the ICU following multi-organ trauma, with complications of pregnancy and due to sepsis. Other more frequent causes of ICU admissions in non-ventilated patients were poisonings and acute neurological disorders (Table II).

The APACHE II score was calculated on ICU admission in $50.1 \%$ of non-ventilated patients and in $51.5 \%$ of patients in the remaining ICU population. The admission APACHE II score was significantly lower in non-ventilated patients (13.0 \pm 7.1 vs.
$23.7 \pm 8.6$ points, $p<0.001)$. Neurological condition expressed by the mean Glasgow Coma Scale on admission was better among non-ventilated patients: $13.7 \pm 2.4$ vs. $6.7 \pm 4.1$ points, $p<0.001$ ).

During ICU stay, catecholamines and continuous renal replacement therapy were less frequently used among non-ventilated patients. Non-invasive ventilation was used more often among these patients ( $19.8 \%$ vs. $3.3 \%, p<0.001)$. Comparison of various techniques used during ICU treatment in both groups is shown in Table III.

The ICU mortality rate was much lower among non-ventilated patients than among the remaining population $(7.0 \%$ vs. $46.7 \%, p<0.001)$. The majority of patients were discharged from the ICU in good condition, in contrast to the other group (54.7\% vs. $23.5 \%, p<0.001)$. Duration of ICU stay was shorter among non-ventilated patients (5.2 \pm 6.1 vs. $10.8 \pm 15.0$ days, $p<0.001$ (Table IV).

A multivariable analysis, carried out on the basis of data presented in Tables I, II and Figure 2, indicated that the most important independent predictors for the lack of invasive ventilation at admission and during the ICU stay were: obstetric complications as the primary cause of ICU admission, presence of systemic autoimmune disease, 
Table IV. Discharge and outcome

\begin{tabular}{|c|c|c|c|c|}
\hline Factor & & $\begin{array}{l}\text { Non-ventilated } \\
\quad(n=1233)\end{array}$ & $\begin{array}{l}\text { Ventilated } \\
(n=19135)\end{array}$ & $P$-value \\
\hline \multirow{4}{*}{$\begin{array}{l}\text { General status at ICU } \\
\text { discharge }\end{array}$} & Good & $675(54.7 \%)$ & $4497(23.5 \%)$ & $<0.001$ \\
\hline & Average & $423(34.3 \%)$ & $4927(25.7 \%)$ & $<0.001$ \\
\hline & Severe & $49(4.0 \%)$ & $767(4.0 \%)$ & 0.988 \\
\hline & Death & $86(7.0 \%)$ & $8944(46.7 \%)$ & $<0.001$ \\
\hline \multirow{5}{*}{$\begin{array}{l}\text { Neurological status } \\
\text { (Glasgow Outcome Score) }\end{array}$} & Good & $825(66.9 \%)$ & $5407(28.3 \%)$ & $<0.001$ \\
\hline & Moderate disability & $221(17.9 \%)$ & $2421(12.7 \%)$ & $<0.001$ \\
\hline & Severe disability & $88(7.1 \%)$ & $1435(7.5 \%)$ & 0.680 \\
\hline & Minimally conscious or vegetative & $13(1.1 \%)$ & $928(4.8 \%)$ & $<0.001$ \\
\hline & Death & $86(7.0 \%)$ & $8944(46.7 \%)$ & $<0.001$ \\
\hline \multirow[t]{5}{*}{ Discharge to } & Same hospital - other department & $874(70.9 \%)$ & $7058(36.9 \%)$ & $<0.001$ \\
\hline & Other hospital & $215(17.4 \%)$ & $2640(13.8 \%)$ & $<0.001$ \\
\hline & Long-term facility & $0(0.0 \%)$ & 199 (1.0\%) & $<0.001$ \\
\hline & Home & $58(4.7 \%)$ & 294 (1.5\%) & $<0.001$ \\
\hline & Death & $86(7.0 \%)$ & 8944 (46.7\%) & $<0.001$ \\
\hline
\end{tabular}

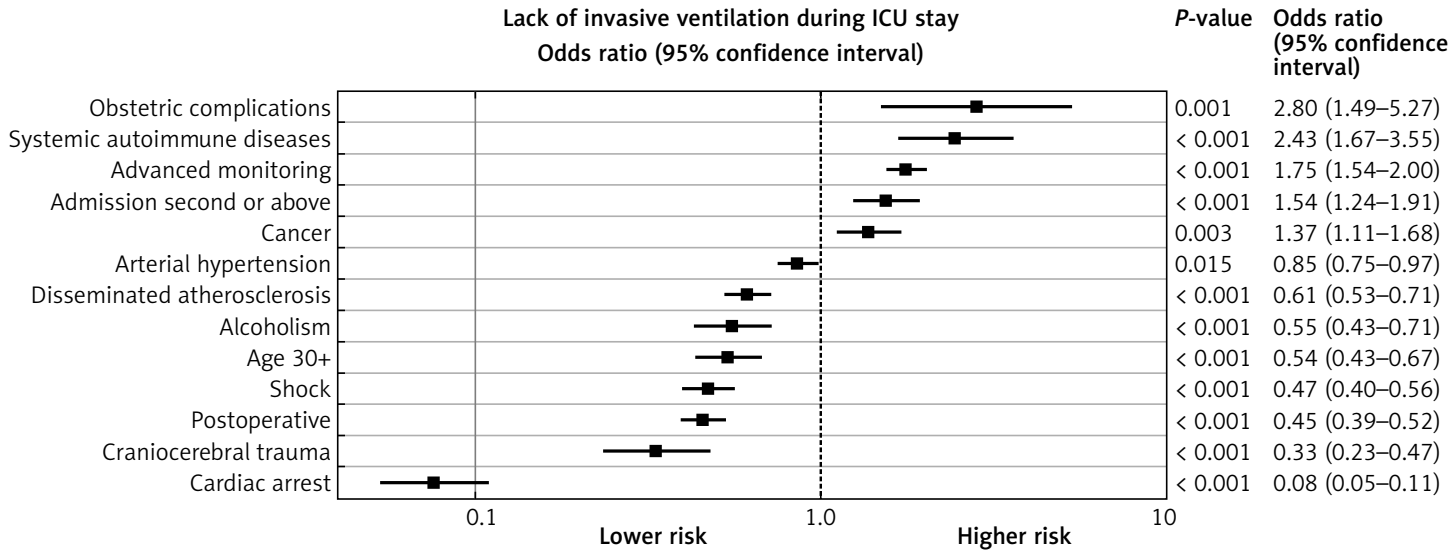

Figure 3. Independent predictors for lack of invasive ventilation in the ICU

invasive monitoring as the primary cause of ICU admission, ICU readmission and the presence of cancer. A full list of independent predictors is presented in Figure 3.

\section{Discussion}

Patients with life-threatening, potentially reversible conditions constitute the group with the highest priority for ICU admission. Apart from such admissions however, there is also a large group of patients at risk of sudden deterioration, requiring intensive monitoring, but otherwise stable. Non-ventilated patients admitted to the ICU usually form a group of "pre-emptive" admissions. This makes it possible to avoid further ICU admis- sions of patients in critical condition, with much lower chances for survival $[8,9,16]$.

Non-ventilated patients constitute a poorly defined population in the ICU. It is not clear what the overall percentage of these patients is. A brief review of the literature indicates that in this respect, observed differences between different countries and various healthcare systems may be enormous $[1,5,17-20]$. One should remember, however, that the observed differences may be primarily associated with significant differences in the position and structure of ICUs in different countries [3, 4, 18].

There are many studies that describe the typical surgical population admitted routinely to the ICU postoperatively [20]. Results from such studies should not be compared to the results from 
this study, as they describe completely different populations. It has to be remembered that our study describes a highly selected population with numerous comorbidities, admitted to the general ICU in life-threatening conditions.

In many developed countries, the concept of having rapid response teams (RRT) or ICU outreach teams in place is becoming increasingly popular. Bannard-Smith et al. analysed data from 51 acute hospitals across Australia, the USA and Western Europe and found that among patients requiring review by the RRT, one in ten died within $24 \mathrm{~h}$, one in four required ICU admission, and one in four had new limitation of therapy implemented [16]. This means that approximately $25 \%$ of patients identified by hospital early warning systems require an admission to the ICU and non-ventilated ICU patients might often be recruited from this group. In Poland, however, the concept of rapid response teams has not yet been adopted [17]. It is therefore not surprising that the percentage of non-ventilated patients in our study was low.

Would it then be safe to say that there are more non-ventilated ICU patients in Western countries in comparison with Poland? It is extremely difficult to answer this question. There has been no research published focusing on this particular subject; therefore, to make comparisons, we decided to analyse data describing ICU treatment due to various reasons [21-24].

In the analysis of 334238 admissions to general ICUs in Japan, invasive ventilation was used only in $23.3 \%$ of patients [22]. Harrison et al. [24] presented data on 129647 admissions to 128 adult general ICUs in the UK. No data on ventilated or non-ventilated patients were given, but the average APACHE II score of all patients was only 16.5 points, so it was much closer to the mean APACHE II score of our non-ventilated patients (13.0 points) than to the mean score of our ventilated patients (23.7 points).

In a multicentre, prospective, cohort study, 773 adult patients were admitted to 45 ICUs over a two-month period in Brazil [21]. Only subjects requiring respiratory support for more than $24 \mathrm{~h}$ during the first 48 hours of ICU stay were included. Overall, 5573 of 7465 patients were excluded, so it may be assumed that approximately $75 \%$ of patients admitted to Brazilian ICUs were non-ventilated and remained non-ventilated for the first $24 \mathrm{~h}$ of their ICU stay. These figures are much higher compared to our data. The rate of comorbidities and overall ICU mortality rates in ventilated patients in Brazil were however quite similar to our ICU population (34\% and $42 \%$, respectively) [21].

We therefore tried to find any information available (given in a direct and indirect form) enabling us to assess the percentage of these pa- tients in other studies. However, this was difficult, as studies available in the literature (from various countries) did not aim to describe the epidemiology of this issue. Information on the percentage of non-ventilated patients in the ICUs in different countries was eventually found only in a small number of studies and was variable: $43 \%$ [5], 56\% [20], 61-79\% [4], 75\% [21] and 77\% [22].

Vincent et al. compared patients with acute respiratory failure requiring and not requiring mechanical ventilation [19]. Patients requiring mechanical ventilation were older, more commonly with infections. Similarly to our invasively ventilated population, the length of ICU stay was also longer and the ICU mortality rate was more than double [19]. There were similar trends in the study by Franca et al. [5]. In our study, non-ventilated patients were also younger and were in a better general condition in comparison to the remaining ICU population.

Interestingly, among our non-ventilated patients we found a higher fraction of patients readmitted to the ICU $(8.6 \%$ vs. $5.4 \%, p<0.001)$. This is surprising, as a more severe course and worse outcomes should generally be expected in this group [11]. This low trigger for readmissions may be related to the fact that patients discharged from Polish ICUs are treated with special attention following their transfer to the general or surgical wards. A high ICU mortality rate amongst those patients, that the staff are aware of, may be influencing decisions about readmission to the ICU.

We found that a significantly higher percentage of non-ventilated patients were admitted to the ICU due to obstetric complications, multiorgan trauma, sepsis, poisonings and acute neurological disorders. In a systematic review published in 2010 by Pollock et al., pregnant or postpartum women accounted for $0.4-16.0 \%$ of ICU admissions [25]. In Poland, these percentages were significantly lower. Admitting a pregnant woman to the ICU in Poland is extremely rare $(0.2 \%$ of analysed hospitalizations); therefore the trigger for ICU admission was probably very low and there might have been more pre-emptive admissions in this group. This resulted in a higher percentage of non-ventilated patients in this cohort.

It is worth paying attention to the fact that patients admitted to the ICU following cardiac arrest were also rarely found in the non-ventilated group, while among the remaining patients they constituted over a quarter of the population (2.6\% vs. $26.8 \%, p<0.001)$. Cardiac arrest is a common cause of ICU admissions worldwide and our results are comparable to those observed in the literature in this regard. In Western Europe, for example, this percentage is 35\% [26], and in the developed Far East countries it is about 25\% [23]. Cardiac arrest usually occurs shortly before ICU 
admission, and therefore probably the percentage of non-ventilated patients in this group was significantly low.

The non-ventilated patients who died in the ICU form a mysterious group in our registry. Such a scenario applied only to $0.4 \%$ of our general ICU population. It is possible that these are the few patients who were admitted to the ICU in a terminal condition with formal or informal do-not-resuscitate orders. There might be however also a substantial number of such patients among survivors in the non-ventilation arm of our study. Unfortunately, we are not able to identify those patients, as such information was not available in our registry. Wilson et al. analysed 27 studies evaluating 2020 patients with do-not-intubate orders [27]. He found that the pooled survival of such patients was $56 \%$ at hospital discharge and $32 \%$ at one year. $\mathrm{He}$ also pointed out that there were no studies to date evaluating quality of dying in non-survivors with do-not-intubate orders. It may be particularly interesting to explore this issue in Poland, as the official Polish Society of Anaesthesiology and Intensive Therapy guidelines on futile therapy published in 2014 [28] are still being ignored by many intensivists due to uncertainty regarding the legal consequences and/or pressure from other departments and the hospital administration [3].

Independent variables influencing being nonventilated in the ICU in Poland were: obstetric complications as the primary cause of ICU admission, presence of systemic autoimmune disease, invasive monitoring as the primary cause of ICU admission, ICU readmission and the presence of cancer. All these identified variables clearly indicate that being non-ventilated in Poland is simply associated with a lower (e.g. earlier) "trigger" for ICU admission. Conclusions that may be drawn from this fact are more than obvious and are reliable. This is important, as univariate analyses carried out retrospectively, using large databases, sometimes yield unexpected results and should be always confirmed by multivariate analysis with the identification of independent variables [29].

When discussing issues regarding the care provided in Polish ICUs, organisational aspects also have to be taken into account. In a recent retrospective study performed by Weigl et al., the authors aimed to identify variables associated with ICU survival, with a focus on their structure. In this impressive, nationwide, big-data study, 48282 adult ICU patients treated in 347 Polish ICUs were analysed [1]. Structural variables associated with ICU survival in the multiple logistic regression analysis were the tertiary level of care and higher annual ICU patient volume. The authors hypothesized that a potential reason for this survival benefit may be the mandatory nurse-to-patient ratio of at least $1: 2$.
Our study has several important limitations. One of them undoubtedly is the incomplete representativeness of the sample (not all Silesian ICUs report to the Silesian ICU Registry). Another limitation is the lack of clear definitions for some concepts used during the early years of the registry. Comparison of groups would also be more objective with the aim of propensity score analysis, although it would radically limit the sample size [30]. The strengths of the study, however, are the large population sample, a relatively broad representation of intensive care units (variously profiled) and a low number of patients excluded due to incomplete data.

In conclusion, characteristics of patients who are not invasively ventilated at admission and throughout the whole ICU stay contribute to the fact that there is a greater chance of a favourable outcome in this population. In particular, this applies to patients readmitted to the ICU, admitted to the ICU due to obstetric complications or for invasive monitoring, and to patients with autoimmune disease or cancer.

On the basis of the data presented it can also be confirmed that ICU mortality in Poland is high, but this is due to a serious systemic error in the structure of ICU admissions. Correction of this error requires profound administrative and educational changes. Increasing the number of patients who have both a high potential for favourable outcome and might benefit most from ICU admission is undoubtedly a step in the right direction.

\section{Acknowledgments}

The authors would like to thank their colleagues from departments reporting to the registry in the past, not included in the active list of Silesian ICU Registry Investigators. According to the number of hospitalisations reported to the registry, ICUs of the following hospitals (with the head of each department) should be mentioned in the following order: District Specialist Hospital in Rybnik (Andrzej Pluta, MD); Specialist Hospital in Tarnowskie Góry (Bronisława Janik, MD); District Specialist Hospital No. 2 in Jastrzębie-Zdroj (Jarosław Mamak MD, PhD); District Hospital in Bielsko-Biała (Prof. Dariusz Maciejewski, MD, PhD); Specialist Hospital in Jaworzno (Anna Tomala, MD, PhD); Public Health Care Centre in Rydułtowy and Wodzisław Śląski (Andrzej Moczała, MD); Municipal Hospital in Siemianowice Śląskie (Joanna Matysik, MD); District Hospital of Trauma Surgery in Piekary Śląskie (Jacek Majewski, MD, PhD); Municipal Health Care Facilities in Żory (Marcin Morawski, MD); University Hospital No. 1, Medical University of Silesia (Prof. Hanna Misiołek, MD, PhD); Edmund Wojtyła General Hospital in Bielsko-Biała (Janusz Gruszczyk, MD); Municipal 
Hospital in Częstochowa, Mirowska 15 (Bartłomiej Gworys, MD); Dr Jozef Rostka District Hospital in Raciborz (Marek Olech, MD); Hospital in Pszczyna (Wojciech Teodorczyk, MD); Knights Hospitaller Hospital in Katowice (Bohdan Seifert, MD, PhD).

The authors also wish to thank Mrs. Jolanta Cieśla for editorial help in preparing the manuscript.

\section{Conflict of interest}

The authors declare no conflict of interest.

\section{References}

1. Weigl W, Adamski J, Goryński P, Kański A, Hultström M. ICU mortality and variables associated with ICU survival in Poland: a nationwide database study. Eur J Anaesthesiol 2018; 35: 949-54.

2. Weigl W, Adamski J, Goryński P, Kański A, Hultström M. Mortality rate is higher in Polish intensive care units than in other European countries. Intensive Care Med 2017; 43: 1430-2.

3. Knapik P, Krzych $Ł$ J, Weigl W, Adamski J, Hultstöm M. Mortality rate in Polish intensive care units is lower than predicted according to the APACHE II scoring system. Intensive Care Med 2017; 43: 1745-6.

4. Wunsch H, Wagner J, Herlim M, Chong DH, Kramer AA, Halpern SD. ICU occupancy and mechanical ventilator use in the United States. Crit Care Med 2013; 41: 2712-9.

5. Franca SA, Toufen C Jr, Hovnanian AL, et al. The epidemiology of acute respiratory failure in hospitalized patients: a Brazilian prospective cohort study. I Crit Care 2011; 26: 330.e1-8.

6. Bellani G, Laffey JG, Pham T, et al. Epidemiology, patterns of care, and mortality for patients with acute respiratory distress syndrome in intensive care units in 50 countries. JAMA 2016; 315: 788-800.

7. Renaud B, Brun-Buisson C, Santin A, et al. Outcomes of early, late, and no admission to the intensive care unit for patients hospitalized with community-acquired pneumonia. Acad Emerg Med 2012; 19: 294-303.

8. Cardoso LT, Grion CM, Matsuo T, et al. Impact of delayed admission to intensive care units on mortality of critically ill patients: a cohort study. Crit Care 2011; 15: R28.

9. Molina JA, Seow E, Heng BH, Chong WF, Ho B. Outcomes of direct and indirect medical intensive care unit admissions from the emergency department of an acute care hospital: a retrospective cohort study. BMJ Open 2014; 4: e005553.

10. Lee JR, Kim EM, Kim SA, Oh EG. A systematic review of early warning systems' effects on nurses' clinical performance and adverse events among deteriorating ward patients. J Patient Saf 2018; doi: 10.1097/ PTS.0000000000000492 [In press].

11. Kareliusson F, De Geer L, Tibblin AO. Risk prediction of ICU readmission in a mixed surgical and medical population. J Intensive Care 2015; 3: 30.

12. Thomas K, VanOyen Force M, Rasmussen D, Dodd D, Whildin S. Rapid response team: challenges, solutions, benefits. Crit Care Nurse 2007; 27: 20-7.

13. Alam N, Hobbelink EL, van Tienhoven AJ, van de Ven PM, Jansma EP, Nanayakkara PW. The impact of the use of the Early Warning Score (EWS) on patient outcomes: a systematic review. Resuscitation 2014; 85: 587-94.

14. Piers RD, Azoulay E, Ricou B, et al. Perceptions of appropriateness of care among European and Israeli inten- sive care unit nurses and physicians. JAMA 2011; 306: 2694-703.

15. Krzych ŁJ, Czempik PF, Kucewicz-Czech E, Knapik P. Silesian Registry of Intensive Care Units. Anaesthesiol Intensive Ther 2017; 49: 73-5.

16. Bannard-Smith J, Lighthall GK, Subbe CP, et al. Clinical outcomes of patients seen by Rapid Response Teams: a template for benchmarking international teams. Resuscitation 2016; 107: 7-12.

17. Adamski J, Goraj R, Onichimowski D, Gawlikowska E, Weigl W. The differences between two selected intensive care units located in central and northern Europe - preliminary observation. Anaesthesiol Intensive Ther 2015; 47: 117-24.

18. Prin $M$, Wunsch $H$. International comparisons of intensive care: informing outcomes and improving standards. Curr Opin Crit Care 2012; 18: 700-6.

19. Vincent JL, Akça S, De Mendonça A, et al. The epidemiology of acute respiratory failure in critically ill patients. Chest 2002; 121: 1602-9.

20. Serafim RB, Dutra MF, Saddy F, et al. Delirium in postoperative nonventilated intensive care patients: risk factors and outcomes Ann Intensive Care 2012; 2: 51.

21. de Azevedo JR, Montenegro WS, Rodrigues DP, et al. Long-term cognitive outcomes among unselected ventilated and non-ventilated ICU patients. I Intensive Care 2017; 5: 18 .

22. Sasabuchi $Y$, Yasunaga $H$, Matsui $H$, et al. The dose-response relationship between body mass index and mortality in subjects admitted to the ICU with and without mechanical ventilation. Respir Care 2015; 60: 983-91.

23. Yang YS, Lee YT, Huang TW, et al. Acinetobacter baumannii nosocomial pneumonia: is the outcome more favorable in non-ventilated than ventilated patients? BMC Infect Dis 2013; 13: 142.

24. Harrison DA, Brady AR, Rowan K. Case mix, outcome and length of stay for admissions to adult, general critical care units in England, Wales and Northern Ireland: the Intensive Care National Audit \& Research Centre Case Mix Programme Database. Crit Care 2004; 8: R99-111.

25. Pollock W, Rose L, Dennis CL. Pregnant and postpartum admissions to the intensive care unit: a systematic review. Intensive Care Med 2010; 36: 1465-74.

26. Berdowski J, Berg RA, Tijssen JG, Koster RW. Global incidences of out-of-hospital cardiac arrest and survival rates: systematic review of 67 prospective studies. Resuscitation 2010; 81: 1479-87.

27. Wilson ME, Majzoub AM, Dobler CC, et al. Noninvasive ventilation in patients with do-not-intubate and comfort-measures-only orders: a systematic review and meta-analysis. Crit Care Med 2018; 46: 1209-16.

28. Kübler A, Siewiera J, Durek G, Kusza K, Piechota M, Szkulmowski Z. Guidelines regarding the ineffective maintenance of organ functions (futile therapy) in ICU patients incapable of giving informed statements of will. Anaesthesiol Intensive Ther 2014; 46: 215-20.

29. Budzyński J, Tojek K, Wustrau B, et al. The "cholesterol paradox" among inpatients - retrospective analysis of medical documentation. Arch Med Sci Atheroscler Dis 2018; 3: e46-e57.

30. Arundel C, Sheriff H, Bearden DM, et al. Discharge home health services referral and 30-day all-cause readmission in older adults with heart failure. Arch Med Sci 2018; 14: 995-1002. 